\title{
Perfil científico y humano de Charles Darwin
}

\author{
Oswaldo Báez Tobar
}

Universidad Central del Ecuador. oswaldobaez@hotmail.com

Charles Darwin nació en Shrewsbury el 12 de febrero de 1809 en el núcleo de una familia culta y acomodada de Inglaterra de principios del siglo XIX. Su abuelo Erasmo y su padre Roberto que fueron médicos de prestigio orientaron a Charles a la carrera de medicina. Así fue como inició estudios de medicina en la universidad de Edimburgo, pero no le entusiasmó la medicina, pues su interés verdadero fueron las ciencias naturales y la colección de especímenes botánicos y zoológicos.

El profesor y naturalista Robert Grant que sustentaba los postulados evolutivos de Lamarck le deleitaba a Darwin con largas explicaciones sobre los cambios evolutivos que se podían observar en la naturaleza y que esperaban ser dilucidados por la ciencia. Así fue que Darwin se inició como naturalista, colector y observador de la naturaleza, a la vez que se interesó por las ideas transmutacionistas (término que se empleaba en esa época para referirse a los cambios evolutivos).

Luego de abandonar los estudios de medicina su padre le orientó a la teología. Ingresó a estudiar las órdenes eclesiásticas de la Iglesia anglicana en Cambridge donde obtuvo la licenciatura; empero su verdadero interés fueron las ciencias de la naturaleza, por lo que decidió tomar cursos de geología, botánica y zoología en la misma universidad. Los años de estudio en Cambridge fueron determinantes para su preparación científica.

En la formación científica de Darwin influyeron el botánico John Henslow y el geólogo Adam Sedgwic. Henslow se convirtió en su tutor y maestro. El interés por la geología le llevó a asistir a las conferencias de Sedgwich y a acompañarle a las exploraciones geológicas; de él recuerda esta frase: "La ciencia consiste en agrupar hechos de tal manera que de ellos se puedan deducir leyes". Se destaca también la influencia del geólogo Charles Lyell que le permitió entender la antigüedad e historia geológica de la Tierra y con ello configurar el marco geológico cambiante de la corteza terrestre en cuyo escenario se habría producido la transmutación de los organismos.

Pero fue John Henslow quien descubrió en Darwin una singular inclinación por la investigación e interés por coleccionar rocas, fósiles, plantas y animales de todo tipo. Por estos atributos le sugirió al capitán FitzRoy que le acepte como naturalista del Beagle en el viaje de estudio alrededor del mundo. El Beagle fue el barco de la Armada del Reino Unido encargado de realizar investigaciones oceanográficas en las costas de varios con- 
tinentes. El capitán FitzRoy cedió un espacio en su camarote al joven naturalista Charles Darwin para el viaje que le provocó un cambio radical en la comprensión de los seres vivientes.

El Beagle zarpó de Davenport el 27 de diciembre de 1831. A esa fecha Charles Darwin tenía 22 años. "El viaje en el Beagle ha sido con mucho el acontecimiento más importante de mi vida y ha determinado toda mi carrera. Le debo a la travesía la primera educación real de mi mente. Me vi obligado a prestar atención a diversas ramas de la historia natural y gracias a eso perfeccionar mi capacidad de observación. La investigación de cada uno de los lugares visitados fue mucho más importante puesto que entra en juego el razonamiento", afirmó Darwin en su autobiografía.

El Beagle recorrió las costas de América del Sur y visitó las Islas Galápagos, en donde realizó las observaciones más importantes de su viaje, lo que se deduce de esta expresión: "Había quedado gratamente impresionado por algunas de las especies del Archipiélago. Estos hechos son el origen de todos mis puntos de vista". Estas y otras expresiones permiten afirmar que Darwin concibió las ideas claves de su Teoría en las observaciones de la flora y fauna galapagueñas; por esta razón histórica, el Ecuador se halla vinculado al origen de la teoría evolutiva.

Luego de cinco años de estudio de geología, paleontología, biogeografía y la flora y fauna mundial retornó a Inglaterra y se dedicó 20 años a organizar las colecciones y a clasificarlas, a escribir libros y artículos científicos, pero sobre todo a formular y estructurar la Teoría de la Evolu- ción Biológica por selección natural, que le diera fama y prestigio en el mundo científico de la época, fama y prestigio que trascendió las fronteras y venció el tiempo.

La Teoría de la Evolución es la teoría más amplia y general de la vida: explica el origen de las especies, la diversidad de los seres vivos y la adaptación al medio ambiente. Por su amplitud, la Teoría se convirtió en el eje articulador y unificador de la biología, pues, integró múltiples hechos y fenómenos del mundo viviente, relacionó los principios y conceptos de las ciencias biológicas. Pero sobre todo posibilitó la construcción de una nueva visión del mundo natural y de la humanidad, por lo cual la teoría evolutiva constituye uno de los ejes del pensamiento moderno.

En 1859, Darwin publicó el libro El Origen de las Especies que contiene una amplia argumentación de la Teoría de la Evolución. "La Teoría tiene grandeza y claridad y consecuencias demostrables", afirmó Darwin en el ocaso de su vida.

Lo que sorprende en Darwin es su pasión por la verdad, la amplitud y profundidad de sus logros durante los 50 años de actividad científica, durante los cuales hizo importantes contribuciones científicas en el campo de la geología, la paleontología, la botánica, la zoología, la taxonomía científica, la historia natural y la evolución orgánica, con lo cual incidió en otras ciencias naturales e influyó en las ciencias sociales.

Darwin murió el 19 de abril de 1882 a la edad de setenta y tres años. Fue enterrado junto a Isaac Newton. De esa manera acabaron unidos los dos mayores científicos de la historia de Inglaterra. Newton 
abrió la puerta a la comprensión racional de la naturaleza y a su control tecnológico; Darwin dio paso a la comprensión racional del hombre y de su lugar en el mundo, así como a la posibilidad de mejorar la condición humana, según expresión de Julian Huxley.

\section{BIBLIOGRAFÍA}

Darwin, C. 1993. Autobiografia. Alianza Editorial, S.A. Madrid, España.

Huxley, J., Kettlewel, H. B. D. 1984. Darwin. Salvat Editores, S.A. Barcelona, España.

Caro-Enao, L. E. 2004. Charles Darwin. Una vida en busca de la vida. Panamericana Editorial Ltda. Bogotá, Colombia. 